\title{
Planejamento estratégico como um dos fatores de sucesso das organizações esportivas: um estudo sobre os clubes esportivos brasileiros que atuam no contexto olímpico
}

\section{RESUMO}

O sucesso de uma organização esportiva depende de diversos fatores, um deles é a estruturação de um planejamento estratégico. Este estudo teve como objetivo principal identificar a existência e analisar importância do planejamento estratégico nos principais clubes esportivos brasileiros que atuam em nível Olímpico. Como resultado, foi possível constatar que os clubes brasileiros analisados possuem planejamentos e seguem com afinidade e coerência recomendações existentes na literatura. E este fato é um indício que o planejamento é o primeiro e um dos passos para se alcançar sucesso, seja ele administrativo ou esportivo. Outros fatores acabam por existir e influenciar o modo operante de organizações brasileiras, como neste caso, clubes esportivos. Por outro lado, é fundamental que o planejamento estratégico, passe a existir no esporte brasileiro, a fim de que este tenha um maior e melhor profissionalismo em termos organizacionais.

PALAVRAS-CHAVE: Planejamento estratégico; Clubes esportivos; Gestão profissional
Paulo Henrique Marques Araujo Graduação em Ciências do Esporte Universidade Estadual de Campinas -

UNICAMP

Faculdade de Ciências Aplicadas Limeira, São Paulo, Brasil paullo.marquess@gmail.com https://orcid.org/0000-0001-6243-6940

\section{Guilherme Kioshi Yamanaka} Especialização em Gestão: Comercial Universidade Estadual de Campinas UNICAMP

Faculdade de Educação Física Campinas, São Paulo, Brasil guilhermek.yamanaka@gmail.com https://orcid.org/0000-0001-8529-6522

Leandro Carlos Mazzei Doutor em Educação Física Universidade Estadual de Campinas UNICAMP

Faculdade de Ciências Aplicadas Limeira, São Paulo, Brasil lemazzei@unicamp.br ${ }^{0}$ https://orcid.org/0000-0002-0788-4668 


\title{
Strategic planning as one of the success factors of sports organizations: an study about Brazilian sports clubs operating in the Olympic context
}

\begin{abstract}
The success of a sports organization depends on several factors, one of them is the structuring of a strategic plan. The main objective of this study was to identify the existence and analyze the importance of strategic planning in Brazilian sports clubs that operate at the Olympic level. As a result, it was possible to verify that Brazilian clubs have plans and follow the recommendations in the literature with affinity and consistency. And this fact is an indication that strategic planning is the first step towards administrative or sports success. Other factors influence the way in which Brazilian sports clubs operate. However, it is essential that strategic planning comes to exist in Brazilian sport, for greater and better professionalism in organizational terms.
\end{abstract}

KEYWORDS: Strategic planning; Sports clubs; Professional management

Planificación estratégica como uno de los factores de éxito de las organizaciones deportivas: un estudio sobre clubes deportivos brasileños que operan en el contexto olímpico

\section{RESUMEN}

Versión en español del resumen. El éxito de una organización deportiva depende de varios factores, uno de ellos es la estructuración de un plan estratégico. El objetivo principal de este estudio fue identificar la existencia y analizar la importancia de la planificación estratégica en los principales clubes deportivos brasileños que operan a nivel olímpico. Como resultado, fue posible verificar que los clubes brasileños tienen planes y siguen las recomendaciones en la literatura con afinidad y consistencia. Y este hecho es una indicación de que la planificación es el primero y uno de los pasos para lograr el éxito, ya sea administrativo o deportivo. Otros factores influyen en la forma en que operan los clubes deportivos brasileños. Sin embargo, es esencial que exista una planificación estratégica en el deporte brasileño, para una mayor y mejor profesionalidad en términos organizacionales.

PALABRAS-CLAVE: Planificación estratégica; Clubes deportivos; Gestión profesional 


\section{INTRODUÇÃO}

A evolução histórica da Gestão do Esporte está relacionada com o contexto social, a necessidade de organização e a "profissionalização" das organizações esportivas, treinadores, atletas e das diferentes atividades e negócios relacionados ao universo esportivo (PIRES; SARMENTO, 2001). No caso, o termo profissionalização remete ao processo em que a atuação dos recursos humanos e uma organização perpassa no sentido de se obter certo nível para alcançar maior habilidade num determinado trabalho capacitado (DICIONÁRIO ONLINE DE PORTUGUÊS, 2020). No Brasil, a profissionalização das organizações esportivas, principalmente dos clubes esportivos, é um processo complexo e que ainda possui espaço para reflexão e evolução (ROCCO JÚNIOR, 2012).

Historicamente, os clubes esportivos no Brasil sempre foram geridos por pessoas cuja dedicação para esta função ocorrera de maneira voluntária, regidos por estatutos elaborados por uma lógica associativa do passado e em muitos casos, ultrapassada para o contexto esportivo moderno (BARROS; MAZZEI, 2012; CARDIA, 2014; MATTAR, 2014). Com a globalização e as pressões por uma melhor organização, se faz necessário que as práticas de gestão de clubes e outras organizações esportivas passem por um processo de profissionalização e/ou modernização (MARQUES; GUTIERREZ; MONTAGNER, 2009; PIRES; SARMENTO, 2001). Afinal, o Esporte é um dos principais fenômenos da humanidade e nada mais coerente que suas atividades possuam cada vez mais a atuação de recursos humanos qualificados, além de apresentarem ética, responsabilidade, sustentabilidade, atitudes democráticas e transparência (CORREIA; BISCAIA, 2019; MAZZEI; ROCCO JÚNIOR, 2017). Assim, a prioridade seria romper paradigmas quanto a importância da gestão do esporte, como exemplifica Campestrine (2016, p. 59): “o conhecimento técnico sobre a gestão é, mais das vezes, aprendido na prática e, em muitas ocasiões, de maneira viciada, sem o devido respaldo acadêmico-científico". De forma que, do contrário, as principais decisões estratégicas a serem tomadas pelos clubes no Brasil, devem possuir um caráter técnico, e também científico, por profissionais capacitados e bem orientados para um desenvolvimento esportivo condizentes com a importância de fenômeno Esporte na sociedade.

Neste sentido, uma das ações que se relacionam com o processo de organização e profissionalização do esporte é a elaboração, a execução e a avaliação do planejamento estratégico das organizações esportivas (MATTAR; MATTAR, 2013; MAZZEI; BASTOS, 2012; ROCCO JÚNIOR, 2012; VANCE; NASSIF; MASTERALEXIS, 2015). Na área da Administração, o conceito de planejamento envolve o desenvolvimento de processos, técnicas e ações gerenciais, as quais proporcionam uma situação viável de predizer as implicações futuras relacionadas com as 
decisões do presente e dos objetivos organizacionais (OLIVEIRA, 2006). Segundo também Oliveira (2006), um bom planejamento irá facilitar a tomada de decisão no futuro, de modo mais rápido, coerente, eficiente e eficaz.

Dentro deste raciocínio, pode-se afirmar que o exercício sistemático do planejamento tenta reduzir a incerteza envolvida no processo decisório e, consequentemente, provocar o aumento da probabilidade de alcance dos objetivos, desafios e metas. Já a vertente "Planejamento Estratégico" significa o ato ou efeito de planejar, ou criar um plano para otimizar a alcance de determinados objetivos (CERTO; PETER, 2005; MAXIMIANO, 2006). Também é preciso considerar que os processos do planejamento, seja estratégico ou não, implicam outros processos decisórios, de forma permanente, somados a um contexto geralmente interdependente e mutável .

Assim, Mintzberg, Ahlstrand e Lampel (2010) contrapõem acerca do planejamento estratégico, apontando circunstâncias que podem impedir uma conclusão desejada. Mesmo com um planejamento estratégico definido, existem alguns detalhes que podem interromper uma boa execução do mesmo, como resultados não alcançados, mudanças no ambiente externo das organizações, dentre outros.

Para elaborar um planejamento estratégico, é necessário um levantamento profundo de uma série de informações, que passa por um diagnóstico principalmente do ambiente organizacional interno, projetando a elaboração de objetivos e desafios em termos administrativos, sociais e esportivos (ROCCO JUNIOR, 2012). Ao mesmo tempo e em uma lógica sistêmica, é preciso que os clubes esportivos enquanto organização, conheçam e monitorem o seu ambiente externo, para que assim o seu planejamento estratégico esteja em sinergia com o contexto onde estão inseridos (PIRES, 2005).

Para Oliveira (2006) a estruturação de um planejamento estratégico pode ser dividida em quatro fases, conforme apresentado no Quadro 1.

Quadro 1 - Fases do Planejamento Estratégico.

\section{Fase I: Diagnóstico estratégico}

Nesta fase, é indicado que a instituição realize uma detalhada pesquisa para avaliar e examinar a realidade interna e externa

\begin{tabular}{|c|c|c|c|}
\hline \multicolumn{4}{|c|}{ examinar a realidade interna e externa } \\
\hline Identificação & Identificação & Análise externa & Análise interna \\
da visão & dos valores & Neste momento, a & Apresenta quais são os pontos \\
Conceituação & Os princípios, & instituição deve ter & forte e fracos da instituição. \\
do que a & ideias e crenças & como base um olhar & Desse modo, deve haver \\
empresa busca & que irão nortear & para fora de si, ou & competência e critérios \\
e/ou quer ser & as decisões da & seja, uma investigação & técnico por parte da gestão do \\
para um futuro & organização & completa para & clube, com o objetivo de \\
determinado. & & identificar qual & analisar os principais pontos \\
& & ambiente o clube está & fortes a serem destacados \\
& & & \multicolumn{2}{|c}{} \\
\hline
\end{tabular}




\begin{tabular}{|c|c|c|c|}
\hline & \multicolumn{2}{|c|}{$\begin{array}{l}\text { inserido, apontando as } \\
\text { reais oportunidades, a } \\
\text { fim de maximizá-las e } \\
\text { identificar as ameaças } \\
\text { que podem prejudicar } \\
\text { a organização. }\end{array}$} & $\begin{array}{c}\text { com a intenção de } \\
\text { potencializar as decisões da } \\
\text { organização; da mesma } \\
\text { forma, os executivos devem } \\
\text { constatar quais os pontos } \\
\text { fracos com a intenção de } \\
\text { minimizá-los. }\end{array}$ \\
\hline \multicolumn{4}{|c|}{ Fase II: Missão } \\
\hline \multicolumn{2}{|c|}{$\begin{array}{l}\text { Missão do clube } \\
\text { É sua razão de ser, existência; O negócio do } \\
\text { clube e a referência a quais atividades o } \\
\text { clube se concentra. }\end{array}$} & \multicolumn{2}{|c|}{$\begin{array}{c}\text { Caráter estratégico } \\
\text { A partir da definição da missão do clube, é } \\
\text { indicado que a organização trace caminhos e } \\
\text { estratégias para o seu cumprimento, } \\
\text { conhecendo sua situação externa e interna. }\end{array}$} \\
\hline \multicolumn{4}{|c|}{$\begin{array}{l}\text { Fase III: Instrumentos Prescritivos } \\
\text { Os instrumentos prescritivos vêm para nortear os conjuntos definidos acerca do diagnóstico } \\
\text { do clube e dentro da missão definida, de acordo com a postura estratégica e a visão }\end{array}$} \\
\hline $\begin{array}{c}\text { Estabelecimento de objetivos } \\
\text { e metas } \\
\text { Objetivos: é o alvo ou situação } \\
\text { que se pretende atingir. Aqui se } \\
\text { determina para onde deve } \\
\text { dirigir seus esforços. } \\
\text { Meta: corresponde aos passos } \\
\text { ou etapas, perfeitamente } \\
\text { quantificados e com prazos } \\
\text { para alcançar os desafios e } \\
\text { objetivos. As metas são } \\
\text { decomposições dos objetivos } \\
\text { ao longo do tempo (anos, } \\
\text { semestre, meses). A nível } \\
\text { estratégico, tático e } \\
\text { operacional. }\end{array}$ & \multicolumn{2}{|c|}{$\begin{array}{l}\text { Estabelecimentos de } \\
\text { estratégias } \\
\text { As formas pelo quais } \\
\text { serão definidas uma } \\
\text { direção, a fim de } \\
\text { executar o objetivo e } \\
\text { meta. }\end{array}$} & $\begin{array}{c}\text { Estabelecimentos dos } \\
\text { projetos e planos de ação } \\
\text { Projetos: são trabalhos a } \\
\text { serem realizados com } \\
\text { responsabilidades de } \\
\text { execução, resultados } \\
\text { esperados com quantificação } \\
\text { de benefícios e prazos para } \\
\text { execução preestabelecidos, } \\
\text { considerando os recursos } \\
\text { humanos, financeiros, } \\
\text { materiais e de equipamentos, } \\
\text { bem como as áreas } \\
\text { envolvidas necessárias a seu } \\
\text { desenvolvimento. } \\
\text { Planos de ação: são os } \\
\text { conjuntos das partes comuns } \\
\text { dos diversos projetos quanto } \\
\text { aos assuntos que está sendo } \\
\text { tratado. }\end{array}$ \\
\hline \multicolumn{4}{|c|}{$\begin{array}{l}\text { Na última fase, é chegado o momento de o clube ter a real noção se está conseguindo } \\
\text { cumprir com seu planejamento estratégico, buscando definir parâmetros, indicadores } \\
\text { técnicos, avaliação, controle e revisões periódicas. }\end{array}$} \\
\hline
\end{tabular}

Fonte: Os autores adaptado de Oliveira (2006).

Apesar das fases acima e outros modelos de planejamento estratégico existentes na literatura, não há uma "cartilha" de normas a serem realizadas para obter sucesso e tal característica inclui a inexistência de "fórmulas mágicas" ou "receitas" sobre a gestão e o planejamento estratégico de clubes esportivos (SOTIRIADOU; DE BOSSCHER, 2013). 
Entretanto, é fundamental que a utilização dos conceitos e ideias de outras áreas científicas aplicadas ao Esporte, principalmente da Administração, passem a ser vistas com mais seriedade e com maior frequência. Parece ser a tendência mundial e carência no esporte brasileiro nos últimos anos (MAZZEI; ROCCO JÚNIOR, 2017). Ainda com relação ao Brasil, a principal forma de disseminação do esporte ainda são os clubes sócio-esportivos (MEIRA; BASTOS; BÖHME, 2012; TEIXEIRA et al., 2017). Os clubes são a base do esporte Olímpico brasileiro e um número significativo de atletas da delegação brasileira nos Jogos Olímpicos do Rio 2016 foi composta por atletas destes clubes (COMITÊ BRASILEIRO DE CLUBES, 2016; MARRA, 2016).

Neste contexto, este trabalho tem por objetivo principal identificar a existência e analisar importância do planejamento estratégico nos principais clubes esportivos brasileiros que atuam em nível Olímpico. Dentro da amostra dos clubes selecionados, considerou-se aqueles que tiveram o maior número de atletas na delegação olímpica brasileira dos Jogos Olímpicos Rio 2016, sendo este indicador, uma possível premissa que condiz com um bom desempenho técnico-esportivo e de gestão dessas organizações. Para cumprir o objetivo, foram analisados documentos e realizadas entrevistas com gestores dos clubes. Mais detalhes e informações no decorrer deste artigo e esperase que ao final, os interessados neste tema tenham um maior entendimento sobre a importância do planejamento estratégico e a relação com os clubes selecionados.

\section{MATERIAIS E MÉTODOS}

A metodologia utilizada nesta pesquisa baseou-se na taxionomia apresentada por Vergara (2010), que subdivide os processos metodológicos em dois aspectos: primeiro quantos aos fins e segundo quanto aos meios. Quantos aos fins, a pesquisa será descritiva, pois irá, de certa forma, apresentar características dos clubes esportivos selecionados, propondo em alguns momentos análise sobre a importância do planejamento estratégico destas organizações. Quantos aos meios, a pesquisa se enquadra como documental e de campo, onde realizou-se análise de documentos e entrevistas semiestruturadas que tiveram como foco a identificação e análise da importância do planejamento estratégico dos clubes esportivos pré-selecionados.

Para escolha dos clubes, foi adotado o seguinte critério: o número de atletas na delegação brasileira dos Jogos Olímpicos do Rio de Janeiro em 2016. Desse modo, estiverem no Rio-2016, 465 atletas brasileiros, dos quais 390 (84\%) eram atletas de clubes esportivos. Segundo Marra (2016), os clubes com o maior número de atletas na delegação brasileira foram: Esporte Clube Pinheiros (62), BM\&F Bovespa (21), Minas Tênis Clube (15), SESI-SP (13) e Clube de Regatas do Flamengo (11). Optou-se por divulgar os nomes dos clubes em razão dos mesmos serem 
beneficiados por recursos oriundos do poder público (COMITÊ BRASILEIRO DE CLUBES, 2016; MARRA, 2016).

O Esporte Clube Pinheiros é um clube com amplo prestígio e destaque no cenário nacional, mantenedor e formador de atletas de alto nível esportivo, sendo possível concluir que o grau de desenvolvimento e performance apresentado pelo clube condiz com o número de atletas na delegação brasileira. O BM\&F Bovespa (B3 Atletismo) teve sua extinção em janeiro de 2018, dando fim há um ciclo de 16 anos de existência e de desenvolvimento de atletas de elite no atletismo. O Minas Tênis Clube também é um clube sócio-esportivo que possui a tradição de possuir um número expressivo na formação e manutenção de atletas que integram as delegações brasileiras em eventos esportivos internacionais. O SESI-SP é visto como uma instituição parte do "Sistema S", mas que desde um passado recente tem estimulado a prática esportiva de rendimento, possuindo atletas de elite em seus quadros e assim sendo considerado um clube por muitas confederações nacionais. Por fim, o Clube de Regatas do Flamengo é o único da amostra a ser um clube majoritariamente conhecido pelo futebol, mas que historicamente possui também a tradição em esportes Olímpicos. Assim, o universo amostral foi: Esporte Clube Pinheiros, Minas Tênis Clube, Sesi-SP, e Clube de Resgatas do Flamengo, já que o BM\&F Bovespa (B3 Atletismo) foi extinto. Com este universo amostral definido, partiu-se para a identificação de documentos e elaboração de convites aos gestores dos clubes para a coleta de dados para análise. A coleta dos documentos e entrevistas se deram entre dezembro de 2017 e junho de 2018.

Quanto aos documentos foram identificados nos sites oficiais ou cedidos pelas próprias organizações (após contato) os seguintes materiais: "Plano Diretor de Desenvolvimento 2016-2030" (ESPORTE CLUBE PINHEIROS, 2017); "Gestão Estratégica" - página da internet (MINAS TÊNIS CLUBE, 2017); "Planejamento Estratégico 2007-2011” (SESI-SP, 2007); "Planejamento Estratégico Atualização 2013-2020” (CLUBE DE REGATAS DO FLAMENGO, 2015).

Quanto às entrevistas, a partir da conveniência dos pesquisadores, disponibilidade e aceite de convite dos possíveis entrevistados, elas ocorreram com quatro gestores de dois dos quatro clubes esportivos selecionados como universo amostral. Neste caso, os gestores e clubes terão seus nomes omitidos e resguardados por boas normas de ética de pesquisa. Basicamente três dos entrevistados possuem graduação em Educação Física e outro, graduação em Esporte, dois possuem pelo menos uma pós-graduação Lato sensu (especialização) em área como Psicologia do Esporte, Gestão Educacional, Fisiologia do Exercício e Administração. Um dos profissionais que possui especialização ainda é Mestre em Ciências da Motricidade, e um profissional que não possui especialização é Mestre em Educação Física. Resumindo, além de considerável currículo 
educacional, todos possui ampla experiência profissional com relação ao esporte e a gestão de diferentes situações relacionadas a educação física ou ao esporte.

As entrevistas ocorreram em nos locais de trabalho dos entrevistados, face-a-face com um pesquisador, além de serem gravadas para posteriormente serem transcritas. Todos entrevistados foram informados sobre o objetivo da pesquisa e assinaram termo de consentimento livre e esclarecido sobre a ultimação dos dados da entrevista. Pela sua composição semiestruturada, a entrevista teve questões compostas por um número de temas chave, mas também permitiram a sondagem e elaboração de novas questões relacionadas com os tópicos do problema do artigo (LI; PITTS; QUARTERMAN, 2008). Os temas abordados foram: Fatores de importância, em nível de gestão, para o sucesso esportivo do clube; A existência de um planejamento estratégico (geral e específico para o alto-rendimento) no clube; Itens essenciais para o sucesso de um planejamento estratégico (dado a sua existência), como influenciadores de flexibilização e o processo de avaliação, por exemplo.

As transcrições das entrevistas e os documentos foram analisadas através de Análise de Conteúdo. A Análise de Conteúdo é definida como a identificação de conteúdo presente nas mensagens para se obter indicadores (quantitativos ou não) que permitem a relação com conceitos relativos à determinado tema de pesquisa (LI; PITTS; QUARTERMAN, 2008). Devido a sua natureza qualitativa, a Análise de Conteúdo é considerada um método vantajoso para a identificação e análises de informações de realidades sociais em profundidade, as quais não seriam possíveis através de métodos quantitativos (QUEIRÓS; GRAÇA, 2013).

Os pesquisadores que utilizam a Análise de Conteúdo podem construir as categorias e subcategorias de três formas: fechada, aberta ou mista. Na forma fechada envolve uma abordagem dedutiva, ou seja, as categorias são pré-escolhidas a partir da literatura existente. Na forma aberta, as categorias são construídas durante o andamento da pesquisa. O que também é conhecido como abordagem indutiva, onde os resultados obtidos geram novos conceitos e teorias. Já a forma mista incorpora características das formas abertas e fechadas para a categorização se tornando um tipo de abordagem dedutiva-indutiva. Este tipo citado por último permite adaptações que proporcionar novas contribuições à modelos teóricos existentes (QUEIRÓS; GRAÇA, 2013). Assim, nesta pesquisa, foi utilizada a forma de categorização dedutiva com relação aos documentos analisados, sendo que a organização dos resultados partiu da identificação das fases do planejamento estratégico definidos por Oliveira (2006). Para as entrevistas foi utilizado o processo de categorização mista (dedutiva-indutiva), baseando-se no conceitos do planejamento estratégico definidos por Oliveira (2006), mas aberto à identificação de categorias que proporcionem novas contribuições, de acordo o objetivo do trabalho que é identificar a existência e analisar importância 
do planejamento estratégico dos principais clubes esportivos brasileiros que atuam no contexto Olímpico.

Para o auxílio da organização dos dados para a realização da Análise de Conteúdo, foi utilizado o programa o programa Microsoft Office Excel 2013. O processo de categorização foi realizado por dois pesquisadores independentes que possuíam familiaridade com o tema, com as duas abordagens teóricas utilizadas e com o procedimento de análise escolhido.

\section{RESULTADOS E DISCUSSÕES}

A partir da literatura apresentada e utilizada para a análise dos documentos identificados, houve a identificação dos resultados a partir das quatro fases pertinentes com a definição de um planejamento estratégico segundo Oliveira (2006). O Quadro 2 e consequente legenda (V Verificado; PV - Parcialmente Verificado; X - Não verificado) foram criados para a observação dos resultados.

Quadro 2 - Resultado das análises sobre os documentos dos clubes selecionados.

\begin{tabular}{|c|c|c|c|c|}
\hline $\begin{array}{c}\text { Fase I - Diagnóstico do } \\
\text { Planejamento Estratégico }\end{array}$ & $\begin{array}{l}\text { Esporte Clube } \\
\text { Pinheiros }\end{array}$ & $\begin{array}{c}\text { Minas Tênis } \\
\text { Clube }\end{array}$ & Sesi-SP & $\begin{array}{c}\text { Clube de Regatas } \\
\text { do Flamengo }\end{array}$ \\
\hline Identificação da visão & $\mathrm{V}$ & $\mathrm{V}$ & V & $\mathrm{V}$ \\
\hline Identificação dos valores & V & V & PV & V \\
\hline Análise externa & PV & $\mathrm{X}$ & $\mathrm{V}$ & $\mathrm{V}$ \\
\hline Análise interna & $\mathrm{V}$ & $\mathrm{X}$ & $\mathrm{V}$ & $\mathrm{V}$ \\
\hline Fase II - Missão & $\begin{array}{l}\text { Esporte Clube } \\
\text { Pinheiros }\end{array}$ & $\begin{array}{c}\text { Minas Tênis } \\
\text { Clube }\end{array}$ & Sesi-SP & $\begin{array}{c}\text { Clube de Regatas } \\
\text { do Flamengo }\end{array}$ \\
\hline Missão do clube & $\mathrm{V}$ & $\mathrm{V}$ & V & V \\
\hline Caráter estratégico & $\mathrm{V}$ & $\mathrm{PV}$ & $\mathrm{V}$ & $\mathrm{V}$ \\
\hline $\begin{array}{c}\text { Fase III - Instrumentos } \\
\text { prescritivos }\end{array}$ & $\begin{array}{l}\text { Esporte Clube } \\
\text { Pinheiros }\end{array}$ & $\begin{array}{c}\text { Minas Tênis } \\
\text { Clube }\end{array}$ & Sesi-SP & $\begin{array}{c}\text { Clube de Regatas } \\
\text { do Flamengo }\end{array}$ \\
\hline $\begin{array}{c}\text { Estabelecimento de objetivos } \\
\text { e metas }\end{array}$ & V & PV & V & V \\
\hline $\begin{array}{l}\text { Estabelecimentos de } \\
\text { estratégias }\end{array}$ & V & PV & V & V \\
\hline $\begin{array}{l}\text { Estabelecimento dos projetos } \\
\text { e planos de ação }\end{array}$ & V & PV & V & $\mathrm{V}$ \\
\hline $\begin{array}{c}\text { Fase IV - Controle e } \\
\text { avaliação }\end{array}$ & $\begin{array}{l}\text { Esporte Clube } \\
\text { Pinheiros }\end{array}$ & $\begin{array}{c}\text { Minas Tênis } \\
\text { Clube }\end{array}$ & Sesi-SP & $\begin{array}{c}\text { Clube de Regatas } \\
\text { do Flamengo }\end{array}$ \\
\hline $\begin{array}{c}\text { Definição de parâmetros, } \\
\text { indicadores técnicos, } \\
\text { avaliação, controle e revisões } \\
\text { periódicas }\end{array}$ & V & PV & V & V \\
\hline
\end{tabular}

Legenda: V - Verificado; PV - Parcialmente Verificado; $\mathbf{X}$ - Não verificado.

Fonte: Os Autores. 
Em síntese, sobre os resultados da análise dos documentos, o Esporte Clube Pinheiros é uma referência nacional quando se trata de esporte Olímpico no Brasil, em seus documentos foram verificados 9 dos 10 itens, sendo que somente a "análise externa" foi parcialmente verificada. O que se pode destacar nos documentos destes clubes é um plano em longo prazo (2016-2030); presença de consultoria externa para a elaboração do documento; o apoio de especialistas e gestores do próprio clube e de diferentes épocas; abordagem integrada; cenários; dentre outros:

"momento em que serão definidos os programas, projetos e recursos por meio de planos de ação, a fim de dar rumo para a evolução sustentável planejada de maneira objetiva, factivel, equilibrada e, principalmente, em consonância com o cumprimento da finalidade do Esporte Clube Pinheiros" (ESPORTE CLUBE PINHEIROS, 2017).

Sobre o Minas Tênis Clube, em análise do documento "Gestão Estratégica”, observou-se um número restrito de informações, onde não foi possível uma análise consistente sobre o planejamento estratégico deste clube, muito justificado pela limitação de acesso à demais informações detalhadas. Em seguida, o SESI-SP que não é necessariamente um clube, mas uma organização paraestatal privada que promove o esporte de rendimento. O SESI-SP, assim como o Esporte Clube Pinheiros, foram verificados 9 dos 10 itens, apesar da análise sobre um documento já defasado: "Plano Estratégico 2007-2011". Já o Clube de Regatas do Flamengo teve todos os itens verificados, muito pela reformulação a partir de 2012, e contendo ainda expectativas de médios prazos (2013-2020 e 2021-2025). Destaca-se ainda no Clube de Regatas do Flamengo a consultoria de empresas externas e a busca por uma clara mudança de filosofia na gestão:

"Montar uma equipe de gestores profissionais, com grande reconhecimento de
mercado pela sua competência nas suas áreas de atuação, atuando de forma
independente da politica do clube" (CLUBE DE REGATAS DO FLAMENGO,
2015).

Foi possível identificar ou verificar nos documentos analisados uma série de itens que a teoria preconiza como essencial sobre o desenvolvimento de um planejamento estratégico. Entretanto, algumas ressalvas devem ser realizadas, como por exemplo, a diferença estatutária entre os clubes selecionados, já que existem na amostra clubes, instituição do Sistema $\mathrm{S}$ e clube de futebol. Assim há uma diferença natural nos documentos, sendo alguns mais específicos enquanto outros nem tanto com relação ao tema esporte e o esporte de alto rendimento Olímpico.

Por outro lado, e independente do enquadramento estatutário, de acordo com o quadro, é visto que três dos quatro clubes analisados tiveram boa parte das fases de um planejamento estratégico "verificada". Somente um clube não teve algumas características verificadas e que coincidem com as premissas teóricas de um planejamento estratégico, até em razão das limitações 
do documento utilizado para análise. De qualquer forma, dentre os clubes que constituíram boa parte da delegação brasileira dos Jogos Olímpicos Rio 2016, o que majoritariamente foi verificado em seus respectivos documentos foi a presença de importantes itens e fases ligadas ao planejamento estratégico.

Entretanto, frisa-se que somente a verificação ou não dos itens não é capaz de confirmar a boa ou a má gestão dos clubes. Primeiro, é preciso ver como ocorre o desenvolvimento do planejamento estratégico na prática. Oliveira (2006), ratifica que a tomada de decisão, aliado a um exercício sistemático do planejamento aumenta a probabilidade de acerto nos objetivos e metas traçadas. Zenone (2014) considera que a ausência do planejamento estratégico e sua consequente aplicação/avaliação provoca a falta de credibilidade da organização esportiva no mercado, resultando no distanciamento de patrocinadores e investidores no clube e no seu contexto esportivo. Por outro lado, Mattar e Mattar (2013) afirmam que a não implementação de um planejamento estratégico pode trazer graves consequências as organizações, como por exemplo a continuidade de práticas amadoras, objetivos escusos e o mal desenvolvimento esportivo como consequência principal.

Outra ressalva, é a questão da opção do clube em manter algumas informações em sigilo, e/ou não querer compartilhar com o público o que fora decidido internamente, a fim de preservar suas ações e perdurar sua competitividade no contexto esportivo. Assim, é importante citar que essas organizações são, perante à legislação e ao código civil brasileiro, associações privadas, ou com gestão privada (LINHARES, 2014), mesmo que recebam recursos de origem pública através de diferentes programas de políticas esportivas, como a Lei $\mathrm{n}^{\circ} 13.756 / 2018$, que determinou que 0,5\% da arrecadação líquida das Loteria fosse repassado ao Comitê Brasileiro de Clubes (CBC), além da Lei de Incentivo ao Esporte, que contempla vários projetos submetidos pelos clubes analisados (BRASIL, 2018).

Sobre as Análises de Conteúdo que emergiram a partir das entrevistas, foi possível estabelecer as seguintes categorias: "Importância do Planejamento Estratégico" e "Fatores que influenciam na busca por sucesso esportivo". Em cada categoria, algumas subcategorias foram estabelecidas para uma melhor elucidação dos resultados.

\section{Categoria: importância do planejamento estratégico}

Esta categoria emergiu nos resultados muito pelo objetivo que foi estipulado nesta pesquisa, mas também por uma relação do processo dedutivo a partir dos conceitos de planejamento estratégico citados na literatura. Destaca-se os seguintes trechos dos entrevistados: 
"Planejamento a longo prazo, com possibilidade de ratificar o rumo que você tem levando. Você não pode fazer um planejamento a longo prazo sem primeiro prevê todo esse caminho que você vai levar. Acho que dessa forma você acaba diminuindo os possiveis acidentes de percursos" (Entrevistado 2).

"O planejamento estratégico é uma coisa obrigatória. Então a gente tem a elaboração do planejamento estratégico para cada período de cinco anos, pelo menos. E ele é extensivo" (Entrevistado 1).

"E aí, a partir do desenho desse instrumento, você tem que seguir as diretrizes desse documento, que fazem parte da elaboração dos seus objetivos, da sua missão, da sua visão, dos seus objetivos estratégicos, de como compilar seus resultados, de verificar como que anda a questão dos processos, como que anda o desenvolvimento das pessoas, então tudo isso faz parte de uma ferramenta" (Entrevistado 1).

"O planejamento é um guia. Ninguém na face da Terra executa o planejamento do jeito que idealizou. Se tentar, é frustação total. Ele tem que ter a visão ampla, a gente altera a visão ampla só se uma catástrofe acontecer" (Entrevistado 4).

A partir dos relatos acima, fica praticamente evidente que o planejamento estratégico é uma das partes fundamentais para o sucesso dos clubes que foram analisados. Além do destaque acima, também foram identificadas falas sobre fases do planejamento, respectivamente conotações estratégicas e a necessidade de controle / avaliação, tanto interna como externa:

"Então é um documento obrigatório a ser feito, até por conta dos nossos órgãos
auditores e fiscalizadores. A partir desse planejamento estratégico, são traçados
todos os objetivos estratégicos, e esses objetivos estratégicos têm todo o
acompanhamento de resultado e depois de verificação para fazer os planos de
trabalho anual. Verificar tendências, corrigir rotas. Então é uma coisa formal que
acontece sempre" (Entrevistado 1).

"Tudo gera indicadores no clube. Então, diversas áreas são certificadas pela (certificação externa). Hoje dentro do clube, a administração de esportes olímpicos e formação é certificada. Administração de esportes recreativos é certificada. A escolinha de natação é certificada. Então, essas áreas que têm conexão direta com o esporte são áreas certificadas. Obrigatoriamente elas têm uma série de requisitos que envolvem avaliação, controle, monitoramento" (Entrevistado 4).

"Internamente, ele é muito bem compartilhado. Os indicadores de monitoramento são disseminados mensalmente entre os gestores de cada uma das modalidades. Então tudo isso é acompanhado. Tudo isso é dialogado internamente e a gente tem a figura do gerente que é responsável por gerenciar todas essas informações e construir algo que tem a visão olímpica de formação do clube. Então, internamente isso é muito bem compartilhado, disseminado e de conhecimento. Então, todas as áreas participam deste grande momento e tem este olhar. Ainda que as coisas sejam compartimentadas" (Entrevistado 4).

Em síntese, a categorias "Importância do Planejamento Estratégico" cumpre a premissa que o planejamento estratégico e suas fases são partes primordiais para um melhor profissionalismo e 
melhor organização do esporte. $\mathrm{O}$ fato do universo amostral ser extremamente qualificado comprova este fato, além de confirmar a tendência de que o planejamento estratégico é parte de um processo de melhor organização e profissionalização de organizações esportivas, conforme afirmado por diferentes obras sobre o tema Gestão do Esporte (MATTAR; MATTAR, 2013; MAZZEI; BASTOS, 2012; ROCCO JÚNIOR, 2012; VANCE; NASSIF; MASTERALEXIS, 2015).

\section{Categoria: fatores que influenciam na busca por sucesso esportivo}

Esta categoria emergiu a partir dos relatos dos entrevistados sobre alguns fatos que acabam por influenciar suas ações no dia a dia de suas organizações, e que inclusive influência no planejamento estratégico. Como em cada clube analisado um dos propósitos é ter êxito esportivo, foram identificados diferentes fatores que são importantes na busca pelo cumprimento do que é estabelecido enquanto objetivo. Neste sentido, podemos destacar os seguintes fatores influenciadores identificados: Recursos, Influenciadores "Políticos" e Outros.

Com relação aos Recursos, foram identificados nas entrevistas trechos que remetem a importância de recursos financeiros, materiais/estruturais e principalmente humanos:

"Se a gente pensar em estrutura física, [nome do clube] dá estrutura física. Se você pensar em profissionais competentes, o [nome do clube] dá isso, inclusive com várias equipes interdisciplinares com profissionais altamente gabaritados. Segue a lei (trabalhista). Ou seja, os atletas ou eles são profissionais realmente, ou então a gente, respeita o que a lei diz" (Entrevistado 2).

"Então, a partir do momento que você tem um presidente que aposta, ai você vai ter a inserção disso no planejamento estratégico, você vai ter garantia de orçamento para desenvolvimento e ai você tem que ter gente competente. Então você tem que ter gestão competente, treinador competente, em consequência disso, você vai ter atleta competente. Então eu acho que os fatores são esses, o principal dele é um conselho e uma presidência que entenda o valor da formação esportiva. O nosso sucesso, ou o bom desempenho está voltado a isso também" (Entrevistado $1)$.

"Primeiro ponto e talvez o mais importante deles, é ter uma equipe técnica e altamente qualificada para isso. Essa é a chave do sucesso. Profissional que lida no dia a dia com o atleta. O segundo ponto, é conseguir oferecer estrutura em todos os aspectos. Quando a gente fala de estrutura, a gente fala de espaço para treinamento, espaço para preparação física, apoio nutricional, apoio psicológico, bateria de testes... Moradia, remuneração interessantes, parcerias interessantes, vínculo e relação de parceria com Comitê Olímpico Brasileiro, Comitê Olímpico Internacional, Federação e Confederações então, todo esse relacionamento é importante para ajudar para fazer com que o clube tenha uma organização interna que atenda de fato, as necessidades externas" (Entrevistado 4). 
Com relação aos influenciadores Políticos, em alguns trechos acima pode-se perceber que o contexto, o ambiente em que operam acabam por influências a ações organizacionais dos clubes analisados, ainda pode ser destacados os seguintes trechos com relação a este tema:

"Então, a nossa cultura de aporte, de patrocínio, de parceria, vinculado ao esporte é muito complicada. Ele precisa ser construído. Hoje ela não existe e isso limita recurso financeiro, que limita todas as outras coisas, ou que limita a maior parte das outras coisas. Uma dificuldade que é de relacionamento institucional. A gente tem um problema de cultura de organização institucional, das federações e confederações e órgãos internacionais" (Entrevistado 3).

"O que a gente vê na política nacional de esportes é que as coisas são feitas muito atropeladas, com pouco planejamento, com descontinuidade de programas, com uma dependência muito alta dos recursos públicos, então você acaba tendo um descompasso quanto a isso" (Entrevistado 2).

"Essa questão organizacional do esporte brasileiro e que a gente sofre demais, não só a gente, mas qualquer outra organização. A gente tem um modelo de organização das confederações e de federações que beira ao caos, não temo modelo de governança, você não tem planejamento estratégico, você não tem transparência, invariavelmente tem corrupção. Então esse aspecto externo interfere demais, não só para o Sesi, mas para a comunidade esportiva como um todo no Brasil" (Entrevistado 1).

Por fim, outros fatores identificados são diversos, que vão desde a questão de proporcionar intercambio e participação de atletas em competições, passando por aplicação de conhecimentos científicos nos processos pedagógicos e de treinamento das ações esportivas até a premissa necessária de desenvolvimento de um sistema interno para o esporte de alto rendimento:

"Os 'caras' estudam todas as áreas possiveis e inimagináveis do atleta e que tenha algum tipo de rendimento e impacto no atleta. E colocam todo esse conhecimento a serviço a preparação fisica, da preparação tática, estratégica, da preparação psicológica, da preparação nutricional, do aspecto biomecânico, da correção do movimento e análise de desempenho" (Entrevistado 4).

“...o clube/instituição tem que colocar ele para disputar os campeonatos internacionais, então esse é fator limitador. Porque se a gente tivesse aqui na América do Sul, uma chance de intercambiar com os países daqui porque as viagens são curtas e baratas, a gente teria uma condição de crescimento muito maior. Em contrapartida, quando a gente tem que ir para a Europa, você não consegue ir lá e ficar 20 dias com os atletas competindo e intercambiando em alto rendimento" (Entrevistado 1).

"O projeto piloto começou em [data]. O projeto poliesportivo começou em [data]. Então nós temos modalidades que tem 100\% atletas oriundos da nossa base em menos de 10 anos de vida" (Entrevistado 3).

Interessante citar que vários dos temas identificados na categoria "Fatores que influenciam na busca por sucesso esportivo" a partir dos trechos são similares a outros estudos, como por 
exemplo o de de Bosscher et al. (2015) e similares, que se debruçaram sobre fatores que influenciam no alcance do sucesso esportivo. Consequentemente, os resultados identificados nesta categoria confirmam uma tendência de homogeneização nos modelos esportivos relacionados com o esporte de alto rendimento, conforme já relatado por alguns autores (ANDERSEN; RONGLAN, 2012; BERGSGARD et al., 2007; HOULIHAN; GREEN, 2008).

\section{CONCLUSÃO}

Considerando o objetivo principal deste trabalho, é preciso lembrar que o planejamento estratégico é um dos passos, e talvez o primeiro, para a realização de um trabalho profissional e de longo prazo em qualquer segmento, e neste caso, principalmente em organizações esportivas. A literatura e os resultados apresentados proporcionam um cenário de benchmarking (ou seja, soluções que já foram feitas por outras organizações que buscaram um objetivo semelhante), no sentido de que se exemplificou boas práticas de gestão a serem tomadas por demais organizações esportivas brasileiras.

Além da importância do planejamento estratégico para os clubes, é fundamental mencionar que a elaboração deste não pode ser tratada de maneira engessada, pelo contrário, as organizações deve considerar o ambiente na qual estão inseridas, compreendendo demais fatores internos, externos e aqueles inerentes ao esporte de alto rendimento que provavelmente existem, mas que necessitam de uma identificação específica à organização ou esporte em questão.

Por fim, esta pesquisa apresenta algumas limitações, como por exemplo os pontos fracos da abordagem qualitativa utilizada nas análises, o que tornam os resultados ligeiramente subjetivos. Além do número amostral reduzido, principalmente quanto às entrevistas. Futuras pesquisas podem aprofundar o tema abordando outras premissas para o sucesso de organizações esportivas, como por exemplo, temas ligados à governança, trabalhos de logo prazo, e outros ligados ao maior e melhor profissionalismo do esporte brasileiro.

\section{REFERÊNCIAS}

ANDERSEN, Svein S.; RONGLAN, Lars Tore. Same ambitions - different tracks: a comparative perspective on Nordic elite sport. Managing Leisure, [S. 1.], v. 17, n. 2-3, p. $155-169,2012$.

BARROS, José Arthur; MAZZEI, Leandro Carlos. Gestão de Clubes Esportivos. In: MAZZEI, Leandro Carlos; BASTOS, Flávia da Cunha (org.). Gestão do Esporte no Brasil: Desafios e Perspectivas. São Paulo: Ícone Editora, 2012. p. 91-118. 
BERGSGARD, Nils Asle; HOULIHAN, Barrie; MANGSET, Per; NODLAND, Svein Ingve; ROMMETVEDT, Hilmar. Sport Policy: A comparative analysis of stability and change. Oxford: Butterworth-Heinemann, 2007.

BRASIL. Lei no 13.756, de 12 de dezembro de 2018 - Dispõe sobre o Fundo Nacional de Segurança Pública (FNSP), sobre a destinação do produto da arrecadação das loterias e sobre a promoção comercial e a modalidade lotérica denominada apostas de quota fixa, 2018.

CARDIA, Wesley. Marketing esportivo e administração de arenas. São Paulo: Atlas, 2014.

CERTO, Samuel C.; PETER, J. Paul. Administração estratégica. São Paulo: Pearson Prentice Hall, 2005.

CLUBE DE REGATAS DO FLAMENGO. Planejamento Estratégico 2013-2020. Rio de Janeiro: Ernst \& Young, 2015.

COMITE BRASILEIRO DE CLUBES. Diagnóstico da origem da formação dos atletas nas Olimpíadas Rio 2016, 2016. Disponível em:

http://cbclubes.org.br/downloads.php?tipo=paginas\&id=33. Acesso em: 7 fev. 2017.

CORREIA, Abel; BISCAIA, Rui. Gestão do Desporto, Compreender para Gerir. Lisboa: Faculdade de Motricidade Humana, 2019.

DE BOSSCHER, Veerle; SHIBLI, Simon; WESTERBEEK, Hans; VAN BOTTENBURG, Maarten. Successful Elite Sport Policies: An international comparison of the SportsPolicy factors Leading to International Sporting Success (SPLISS 2.0) in 15 nations. Aachen: Meyer \& Meyer Verlag, 2015.

DICIONÁRIO ONLINE DE PORTUGUÊS. Significado de Profissionalização. 2020.

ESPORTE CLUBE PINHEIROS. Plano Diretor de Desenvolvimento 2016-2030. São Paulo: Log e Print Gráfica e Logística S.A., 2017.

HOUliHAN, Barrie; GREEN, Mick. Comparative Elite Sport Development. Systems, Structures and public policy. London: Elsevier, 2008.

LI, Ming; PITTS, Brenda G.; QUARTERMAN, Jerome. Research methods in sport management. Morgantown: Fitness Information Technology, 2008.

LINHARES, Humberto Vinicius Queiroz. Regime jurídico dos contratos no Sistema "S" (SENAI, SENAC, SESI e SESC). 2014. Instituto de Direito Público, Brasília, 2014.

MARQUES, Renato Francisco Rodrigues; GUTIERREZ, Gustavo Luis; MONTAGNER, Paulo Cesar. Novas configurações socioeconomicas do esporte na era da globalização. Journal of Physical Education, [S. 1.], v. 20, n. 4, p. 637-648, 2009.

MARRA, Renan. Com dinheiro público, clubes formam maioria dos medalhistas brasileiros Olimpíada no Rio | FolhaFolha de Sao Paulo, 2016. Disponível em:

http://www1.folha.uol.com.br/esporte/olimpiada-no-rio/2016/08/1807260-com-dinheiro-publicoclubes-formam-maioria-dos-medalhistas-brasileiros.shtml. Acesso em: 8 fev. 2017. 
MATTAR, Fauze Najib; MATTAR, Michel Fauze. Gestão de Negócios Esportivos. Rio de Janeiro: Elsevier, 2013.

MATTAR, Michel Fauze. Na trave: o que falta para o futebol brasileiro ter uma gestão profissional. Rio de Janeiro: Elsevier Campus, 2014.

MAXIMIANO, Antônio César Amaru. Teoria Geral da Administração: da revolução urbana à revolução digital. 6aed. ed. São Paulo: Atlas, 2006.

MAZZEI, Leandro Carlos; BASTOS, Flávia da Cunha. Gestão do Esporte No Brasil: Desafios e Perspectivas. São Paulo: Ícone Editora, 2012.

MAZZEI, Leandro Carlos; ROCCO JÚNIOR, Ary José. Um ensaio sobre a Gestão do Esporte: um momento para a sua afirmação no Brasil. Revista de Gestão e Negócios do Esporte, [S. 1.], v. 2, n. 1, p. 96-109, 2017.

MEIRA, Tatiana de Barros; BASTOS, Flávia da Cunha; BÖHME, Maria Tereza Silveira. Análise da estrutura organizacional do esporte de rendimento no Brasil: um estudo preliminar. Revista Brasileira de Educação Física e Esporte, [S. 1.], v. 26, n. 2, p. 251-262, 2012.

MINAS TÊNIS CLUBE. Gestão Estratégica. 2017.

MINTZBERG, Henry; AHLSTRAND, Bruce; LAMPEL, Joseph. Safári de estratégia: um roteiro pela selva do planejamento estratégico. 2. ed. Porto Alegre: Bookman, 2010.

OLIVEIRA, Djalma de Pinho Rebouças De. Planejamento Estratégico: Conceitos, Metodologias e Práticas. 22. ed. São Paulo: Atlas, 2006.

PIRES, Gustavo Manuel Vaz da Silva. Gestão do Desporto: Desenvolvimento Organizacional. Porto: APOGESD, 2005.

PIRES, Gustavo Manuel Vaz da Silva; SARMENTO, José Pedro Sarmento de Rebocho Lopes. Conceito de Gestão do Desporto. Novos desafios, diferentes soluções. Revista Portuguesa de Ciências do Desporto, [S. 1.], v. 1, n. 1, p. 88-103, 2001.

QUEIRÓS, Paula; GRAÇA, Amândio. A análise de conteúdo (enquanto técnica de tratamento de informação) no âmbito da investigação qualitativa. In: MESQUITA, Isabel; GRAÇA, Amândio (org.). Investigação qualitativa em desporto - vol. 2. Porto: CIFIID, 2013. p. 113-149.

ROCCO JÚNIOR, Ary José. Marketing e Gestão do Esporte. São Paulo: Atlas, 2012.

SESI-SP. Planejamento Estratégico 2007-2011. São Paulo: Sesi-SP, 2007.

SOTIRIADOU, Popi; DE BOSSCHER, Veerle (ORG.). Managing High Performance Sport. London; New York: Routledge, 2013.

TEIXEIRA, Marcelo Resende; MATIAS, Wagner Barbosa; CARNEIRO, Fernando Henrique; MASCARENHAS, Fernando Alves. O programa bolsa atleta no contexto esportivo nacional. Motrivivência, [S. 1.], v. 29, n. 0, p. 92-109, 2017. DOI: 10.5007/2175-8042.2017v29nespp92. 
VANCE, Patrícia de Salles; NASSIF, Vânia Maria Jorge; MASTERALEXIS, Lisa Pike (ORG.). Gestão do Esporte: casos brasileiros e internacionais. Rio de Janeiro: LTC - Grupo Gen, 2015.

VERGARA, Sylvia Constant. Projetos e relatórios de pesquisa em administração. 12. ed. São Paulo: Editora Atlas, 2010.

ZENONE, Luiz Claudio. Marketing Futebol Clube. São Paulo: Atlas, 2014.

\section{NOTAS DE AUTOR}

AGRADECIMENTOS - Não se aplica.

CONTRIBUIÇÃO DE AUTORIA

Concepção do manuscrito: P. H. M. Araujo, L. C. Mazzei, G. K. Yamanaka

Coleta de dados: P. H. M. Araujo, L. C. Mazzei, G. K. Yamanaka

Análise de dados: P. H. M. Araujo, L. C. Mazzei, G. K. Yamanaka

Discussão dos resultados: L. C. Mazzei, P. H. M. Araujo, G. K. Yamanaka

Produção do texto: P. H. M. Araujo, L. C. Mazzei, G. K. Yamanaka

Revisão e aprovação: L. C. Mazzei, P. H. M. Araujo, G. K. Yamanaka

FINANCIAMENTO - Não se aplica.

CONSENTIMENTO DE USO DE IMAGEM - Não se aplica.

APROVAÇÃO DE COMITÊ DE ÉTICA EM PESQUISA - Não se aplica.

CONFLITO DE INTERESSES - Não se aplica.

\section{LICENÇA DE USO}

Os autores cedem à Motrivivência - ISSN 2175-8042 os direitos exclusivos de primeira publicação, com o trabalho simultaneamente licenciado sob a Licença Creative Commons Attribution Non-Comercial ShareAlike (CC BY-NC SA) 4.0 International. Esta licença permite que terceiros remixem, adaptem e criem a partir do trabalho publicado, desde que para fins não comerciais, atribuindo o devido crédito de autoria e publicação inicial neste periódico desde que adotem a mesma licença, compartilhar igual. Os autores têm autorização para assumir contratos adicionais separadamente, para distribuição não exclusiva da versão do trabalho publicada neste periódico (ex.: publicar em repositório institucional, em site pessoal, publicar uma tradução, ou como capítulo de livro), com reconhecimento de autoria e publicação inicial neste periódico, desde que para fins não comerciais e compartilhar com a mesma licença.

\section{PUBLISHER}

Universidade Federal de Santa Catarina. Programa de Pós-Graduação em Educação Física. LaboMídia - Laboratório e Observatório da Mídia Esportiva. Publicado no Portal de Periódicos UFSC. As ideias expressadas neste artigo são de responsabilidade de seus autores, não representando, necessariamente, a opinião dos editores ou da universidade.

\section{EDITORES}

Mauricio Roberto da Silva, Giovani De Lorenzi Pires, Rogério Santos Pereira. 


\section{HISTÓRICO}

Recebido em: 03 de março de 2020.

Aprovado em: 18 de maio de 2020. 